\title{
Simulation of Radionuclide Migration in Groundwater Away from an Underground Nuclear Test
}

A.F.B. Tompson, C.J. Bruton, W,L, Bourcier, D.E. Shumaker, A.B. Kersting, D.K. Smith, S.F. Carle, G.A. Pawloski and J.A. Rard

This article was submitted to Materials Research Society Meeting Boston, MA

November 29-December 3, 1999

U.S. Department of Energy

Lawrence

Livermore

National

Laboratory

December 13, 1999 


\section{DISCLAIMER}

This document was prepared as an account of work sponsored by an agency of the United States Government. Neither the United States Government nor the University of California nor any of their employees, makes any warranty, express or implied, or assumes any legal liability or responsibility for the accuracy, completeness, or usefulness of any information, apparatus, product, or process disclosed, or represents that its use would not infringe privately owned rights. Reference herein to any specific commercial product, process, or service by trade name, trademark, manufacturer, or otherwise, does not necessarily constitute or imply its endorsement, recommendation, or favoring by the United States Government or the University of California. The views and opinions of authors expressed herein do not necessarily state or reflect those of the United States Government or the University of California, and shall not be used for advertising or product endorsement purposes.

This is a preprint of a paper intended for publication in a journal or proceedings. Since changes may be made before publication, this preprint is made available with the understanding that it will not be cited or reproduced without the permission of the author.

This report has been reproduced directly from the best available copy.

Available to DOE and DOE contractors from the

Office of Scientific and Technical Information

P.O. Box 62, Oak Ridge, TN 37831

Prices available from (423) 576-8401

http:/ / apollo.osti.gov/bridge/

Available to the public from the National Technical Information Service

U.S. Department of Commerce 5285 Port Royal Rd., Springfield, VA 22161 http://www.ntis.gov/

OR

Lawrence Livermore National Laboratory Technical Information Department's Digital Library http://www.llnl.gov/tid/Library.html 


\title{
SIMULATION OF RADIONUCLUDE MIGRATION IN GROUNDWATER AWAY FROM AN UNDERGROUND NUCLEAR TEST
}

\author{
A.F.B. TOMPSON *I, C.J. BRUTON *, W.L. BOURCIER *, D.E. SHUMAKER **, \\ A.B. KERSTING †, D.K. SMITH †, S.F. CARLE *, G.A. PAWLOSKI *, J.A. RARD * \\ ${ }^{*}$ Geosciences and Environmental Technologies Division, ${ }^{* *}$ Center for Applied \\ Scientific Computing, † Analytical and Nuclear Sciences Division, Lawrence \\ Livermore National Laboratory, Livermore, California, 94551, II afbt@1lnl.gov
}

\begin{abstract}
Reactive transport simulations are being used to evaluate the nature and extent of radionuclide contamination within alluvium surrounding an underground nuclear test at the Nevada Test Site (NTS). Simulations are focused on determining the abundance and chemical nature of radionuclides that are introduced into groundwater, as well as the rate and extent of radionuclide migration and reaction in groundwater surrounding the working point of the test. Transport simulations based upon a streamline-based numerical model are used to illustrate the nature of radionuclide elution out of the near-field environment and illustrate the conceptual modeling process. The numerical approach allowed for relatively complex flow and chemical reactions to be considered in a computationally efficient manner. The results are particularly sensitive to the rate of melt glass dissolution, distribution of reactive minerals in the alluvium, and overall groundwater flow configuration. They provide a rational basis from which defensible migration assessments can proceed.
\end{abstract}

\section{INTRODUCTION}

There is increasing concern about environmental risks posed by radionuclides produced by underground nuclear tests [1,2]. These risks are dependent, in large part, on the physical and chemical mechanisms that control the extent to which radionuclides are introduced and transported in groundwater. In this paper, we review a series of groundwater flow and streamline-based reactive transport simulations designed to evaluate the impact of some of these processes at the Cambric nuclear test site at NTS. Ultimately, our results will be used as a means to (i) better understand the complex mechanisms involved in radionuclide release and retardation, (ii) design data acquisition strategies for future validation and characterization purposes, and (iii) provide better estimates of radionuclide release for transport simulations designed to assess the fate of radionuclides over longer times and larger spatial scales.

\section{NUCLEAR TEST EFFECTS AND RADIONUCLIDE DISTRIBUTION}

The detonation of an underground nuclear device releases an immense amount of energy that vaporizes the geologic and device-related materials in a local region surrounding the testing point [3-5]. This produces a cavity into which overlying formation materials eventually collapse, creating a vertical "rubble" chimney that may extend to the surface. Compressive shock waves generated by the test will fracture or alter the formation beyond the cavity wall. For tests conducted 
beneath the water table, groundwater will also be vaporized near the explosion point. As temperatures cool and gas pressures dissipate, components of the cavity gasses begin to condense in an order determined by their relative vapor pressures or boiling points. First among these are condensing rock vapors that accumulate into a melt glass puddle at the bottom of the cavity. Groundwater eventually refills the cavity region.

Radionuclides associated with an underground nuclear explosion are derived from the original materials in the device, nuclear reactions connected with the explosion, and activation products created in the geologic medium. Complex dynamic processes occurring milliseconds to hours after detonation will control their chemical nature and spatial distribution. Most radionuclide vapors will be retained in the immediate cavity region by rebounding compressive stresses in the formation. In some cases, small amounts of radionuclides may escape the cavity region as a result of pressure-driven "prompt injection". During cooling, heavier radionuclides with higher boiling points (such as ${ }^{241} \mathrm{Am}$ or ${ }^{239} \mathrm{Pu}$ ) will condense first and largely be incorporated within the melt glass [5]. Lighter radionuclides (such as tritium, ${ }^{3} \mathrm{H}$ ) tend to condense later within a "radioactive" or "exchange" volume surrounding the cavity, typically within 2 to 5 cavity radii about the testing point [3]. Other radionuclides will partially condense both within the melt and the rubble zone. Some radionuclides (such as ${ }^{85} \mathrm{Kr}$ ) may exist only as noncondensible gases and move outside the immediate vicinity of the cavity/chimney system.

Little is known about how radionuclides are distributed within melt glass or exchange volume rubble, nor of their chemical state in the rubble following condensation. Some may become associated with the solids of the chimney or cavity, while others, including the noncondensibles, may become incorporated within pore waters. When groundwater infills the cavity, the "rubble" fractions may form aqueous species or solid phases consistent with the aqueous chemistry and minerals in the rubble.

\section{THE CAMBRIC TEST}

The Cambric nuclear test was conducted at Frenchman Flat in NTS in 1965. Frenchman Flat, located in the southeast corner of the NTS, is an intermountain basin formed by Tertiary-age faulting typical of the Basin and Range physiographic province. The working point and resulting test cavity are centered in Quaternary/Tertiary alluvium, approximately $70 \mathrm{~m}$ beneath the ambient water table and $290 \mathrm{~m}$ beneath the ground surface. The alluvium is composed of interbedded silts, clays, sands and gravels derived largely from silicic volcanic rocks (tuff and rhyolitic lava). Alteration minerals include clinoptilolite, calcite, smectite, illite/muscovite, and iron oxide, all of which may possess sorptive potential.

\section{Site Data and Simulation Approach}

As reviewed in [6-8], the Cambric test had a small yield $(0.75 \mathrm{kt})$ which produced cavity and exchange volumes approximately $10.9 \mathrm{~m}$ and $18 \mathrm{~m}$ in radius, respectively. The melt debris is comprised of approximately 900 metric tons of glass that occupies a bulk region of $400 \mathrm{~m}^{3}$ at the bottom of the cavity, assuming a $10 \%$ porosity $[5,6]$. The Cambric test was the subject of a long term radionuclide migration 
experiment between 1975 and 1991, from which a considerable amount of pertinent chemical and physical data have been obtained [7,8]. The experiment involved the pumping of a nearby well in order to induce the elution of relatively mobile radionuclides (such as ${ }^{3} \mathrm{H},{ }^{36} \mathrm{Cl},{ }^{85} \mathrm{Kr}$, and ${ }^{129} \mathrm{I}$ ). Our simulations were limited to a subset of radionuclides and their migration under ambient (non-pumping) flow conditions. This approach is being pursued largely as a means to develop a framework for estimating radionuclide release and migration here and at other tests at NTS [6].

Table 1: Half-life and derived inventory of selected radionuclides associated with the Cambric test, decay corrected to zero time on May 14, 1965 [6].

\begin{tabular}{ccc}
\hline \hline $\begin{array}{c}\text { Radionuclid } \\
\mathrm{e}\end{array}$ & Half Life (yr) & Derived Inventory (moles) \\
\hline${ }^{3} \mathrm{H}$ & 12.3 & 2.04 \\
${ }^{90} \mathrm{Sr}$ & 28.8 & $3.44 \times 10^{-3}$ \\
${ }^{137} \mathrm{Cs}$ & 30.2 & $1.07 \times 10^{-2}$ \\
${ }^{155} \mathrm{Eu}$ & 4.7 & $8.46 \times 10^{-5}$ \\
${ }^{239} \mathrm{Pu}$ & 24100 & 13.0 \\
${ }^{241} \mathrm{~A} \mathrm{~m}$ & 432 & $5.19 \times 10^{-2}$ \\
\hline \hline
\end{tabular}

Table 1 shows the derived inventory of radionuclides considered in the current simulations, decay corrected to zero time on May 14, 1965 [6]. Because details of the initial radionuclide distribution are uncertain, these inventories were assumed to be uniformly distributed throughout the melt glass and exchange volumes according to the fractional distribution data in Table 2. All tritium is assumed to condense within the water that occupies the pores of the exchange volume and melt glass. The data in Table 2 were estimated from radiochemical diagnostics and thermodynamic properties of the elements. Prompt injection processes are not considered to be important at Cambric.

Table 2: Estimated distribution of selected radionuclides among the glass, rubble, gas, and groundwater at the Cambric test $[2,6]$.

\begin{tabular}{ccccc}
\hline \hline $\begin{array}{c}\text { Radionuclid } \\
\mathrm{e}\end{array}$ & Glass \% & Rubble \% & Gas \% & Water \% \\
\hline${ }^{3} \mathrm{H}$ & & & 2 & 98 \\
${ }^{90} \mathrm{Sr}$ & 25 & 75 & & \\
${ }^{137} \mathrm{Cs}$ & 10 & 90 & & \\
${ }^{155} \mathrm{Eu}$ & 95 & 5 & \\
${ }^{239} \mathrm{Pu}$ & 95 & 5 & \\
${ }^{241} \mathrm{~A} \mathrm{~m}$ & 95 & 5 & \\
\hline \hline
\end{tabular}

Groundwater samples taken from below the cavity were assumed to be representative of water chemistry in the vicinity of the Cambric test. The ambient 
groundwater composition used in the simulations is given in Table 3, and is similar to that of waters from volcanic aquifers at NTS. The redox state of the groundwater was assumed to be controlled by equilibrium with atmospheric oxygen, under which conditions radionuclides tend to be most mobile, leading to conservative estimates of migration.

Table 3: Ambient groundwater chemistry used in simulations.

\begin{tabular}{cc}
\hline \hline Constituent & $\begin{array}{c}\text { Concentration } \\
(\mathrm{mg} / \mathrm{L})\end{array}$ \\
\hline $\mathrm{Na}$ & 63 \\
$\mathrm{~K}$ & 8 \\
$\mathrm{Ca}$ & 16 \\
$\mathrm{Mg}$ & 4 \\
$\mathrm{Sr}$ & 0.24 \\
$\mathrm{HCO}_{3}$ & 177 \\
$\mathrm{Cl}$ & 16 \\
$\mathrm{SO}_{4}$ & 32 \\
$\mathrm{HPO}_{4}$ & 0.31 \\
$\mathrm{SiO}_{2}$ & 65 \\
\hline $\mathrm{pH}$ & 8.0 \\
\hline \hline
\end{tabular}

Radionuclides distributed within the exchange volume were partitioned between pore water and mineral surfaces according to ion exchange and surface complexation reactions. Geochemical speciation calculations were used to identify potential radionuclide-bearing aqueous complexes in Cambric groundwaters, with provision for potential fluctuations in $\mathrm{pH}$ and bicarbonate concentration.

Calculations were also used to identify the most likely radionuclide-bearing solids that might precipitate if saturation were achieved, either in the initial distribution, or during melt glass dissolution. Table 4 summarizes the aqueous species and solids considered in the simulations. Solid solutions and co-precipitation were not provided for in the models, so clinoptilolite and smectite solid solutions are represented by the calcium-rich compositional end members, clinoptilolite-Ca and beidellite-Ca, respectively.

\section{RADIONUCLIDE RELEASE AND RETARDATION MODELS}

Use of the streamline-based reactive transport approach allows the use of detailed equilibrium and kinetic models to describe chemical interactions. Release of radionuclides from melt glass was simulated using a kinetic rate law for glass dissolution. Alteration minerals were allowed to precipitate when saturation limits were reached, and allowed to redissolve if dictated by chemical conditions. Surface complexation, ion exchange and precipitation/dissolution were assumed to control release from the rubble/exchange volume and retardation in the alluvium. Although the framework mineralogy of the alluvium (e.g. quartz, feldspars) was assumed to be inert, surface-active (called reactive) minerals in the alluvium were 
allowed to precipitate and dissolve according to their saturation state, and alter the total sorptive capacity of the reactive minerals accordingly. See [6] and below for more details.

Co-precipitation, solid solutions, colloid-facilitated transport, and changes in redox state were not considered in these simulations, nor was sorption to carbonates. 
Melt glass is a heterogeneous brecciated mixture of vesicular and massive glass that largely retains the chemical composition of the host rock. At Cambric, the glass has a rhyolitic composition with about 75 weight \% silica, similar to the alluvium underlying Frenchman Flat [6,9]. Glass also contains small amounts of radionuclides consistent with data in Tables 1 and 2.

The rate of release of radionuclides from the glass is proportional to the rate at which glass reacts with groundwater, and depends on temperature, $\mathrm{pH}$ and fluid chemistry. In a porous medium, this can be described by an equation of the form

$$
\phi \frac{d c_{j}}{d t}=v_{j} r=v_{j} A_{s} k\left(\prod_{i}^{N} a_{i}^{p_{i}}\right)\left(1-\frac{Q}{K}\right),
$$

where $c_{j}$ is the aqueous concentration of radionuclide $j$ in groundwater, _is the melt glass porosity, $r$ is the intrinsic rate of glass dissolution per unit volume of bulk medium, and ${ }_{-j}$ is a stoichiometric coefficient describing the mole fraction of radionuclide $\mathrm{j}$ in the glass. The rate $(\mathrm{r})$ is dependent on the specific surface area of the glass $\left(\mathrm{A}_{\mathrm{s}}\right)$, a temperature-dependent rate coefficient $(\mathrm{k})$, a dimensionless product factor dependent on the activities $\left(\mathrm{a}_{\mathrm{i}}\right)$ of $\mathrm{N}$ catalytic or inhibitive aqueous species, and an affinity term $(1-\mathrm{Q} / \mathrm{K})$ that provides for a slow-down in the rate resulting from fluid saturation effects. In this work, only the effect of $\mathrm{pH}\left(\mathrm{a}_{\mathrm{H}+}\right)$ is included in the product term, and both the rate coefficient and the exponent were determined from experimental data [10]. In the affinity term, $\mathrm{Q}$ and $\mathrm{K}$ are the activity product and equilibrium constant for the glass dissolution reaction, respectively. In the following simulations, we assume $\mathrm{Q}$ is the activity of $\mathrm{SiO}_{2}(\mathrm{aq})$, and $\mathrm{K}$ is the solubility product for amorphous silica. These parameters provide a conservative estimate of glass dissolution rate. The ambient groundwater was assumed to buffer the $\mathrm{pH}$ at 8 and the temperature was assumed constant at $25^{\circ} \mathrm{C}$.

One of the more critical parameters in (1) is the specific melt glass surface area $\left(A_{s}\right)$. As discussed in [6], our nominal value of $0.5 \mathrm{~cm}^{2} / \mathrm{g}$ (or about $118 \mathrm{~m}^{2} / \mathrm{m}^{3}$ ) was estimated from reactive surface area measurements of fractured glass in waste form canisters [11].

\section{Surface Complexation and Ion Exchange}

Radionuclides partitioned into the "exchange" volume (Table 2) may exist as aqueous species, sorbed species on the surfaces of reactive minerals and colloids, and as discrete solid phases and components of solid solutions. The state of the radionuclide depends on radionuclide concentrations in solution, the presence of reactive minerals, and groundwater chemistry. The initial state of a radionuclide and the chemical processes that retard it will collectively influence radionuclide "release" from the exchange volume and subsequent mobility.

Surface complexation, ion exchange, precipitation and dissolution were assumed to control radionuclide release from the exchange volume and retardation in the alluvium. Reactive minerals in the alluvium include goethite (iron oxide), clinoptilolite (zeolite), and smectite and illite/muscovite (clays). A one-site nonelectrostatic surface complexation model was used to describe $\mathrm{Pu}$ and $\mathrm{Sr}$ sorption onto goethite. Ion exchange was modeled using the ideal Vanselow 
convention. Exchange was considered between $\mathrm{Sr}$ and $\mathrm{Ca}$ on clinoptilolite, $\mathrm{Ca}, \mathrm{Mg}$ and $\mathrm{Sr}$ on smectite, and $\mathrm{Cs}, \mathrm{Na}$, and $\mathrm{K}$ on illite/muscovite [6]. Surface areas and cation exchange capacities were taken from the literature [6] in the absence of sitespecific data.

Given the lack of readily available sorption data for $\mathrm{Eu}$ and Am onto iron oxides and silicates at the time of this work, Eu and Am were not assumed to participate in any sorption reactions. They therefore migrated as tracers in the simulations in the absence of retarding mechanisms.

\section{HYDROLOGIC FLOW AND TRANSPORT}

A simple, steady state groundwater flow model in the vicinity of the Cambric test was developed as an initial basis to forecast radionuclide migration away from the cavity region. The model domain is comprised of a $450 \mathrm{~m}$-long by $360 \mathrm{~m}$-wide by 210 m-deep prismatic block "carved" out of the local alluvium just beneath the water table. It includes the cavity and chimney features of the Cambric test, and encompasses the region influenced by the long-term migration experiment $[7,8]$. The domain was oriented such that its longer side is collinear with the topographical gradient and principal direction of geologic deposition, as well as the apparent (ambient) horizontal hydraulic gradient (about 0.001 in magnitude [7]).

Table 4: Aqueous and solids considered in the reactive transport simulations. Tritium $\left({ }^{3} \mathrm{H}\right)$ was only used in a calibration test and is not included here.

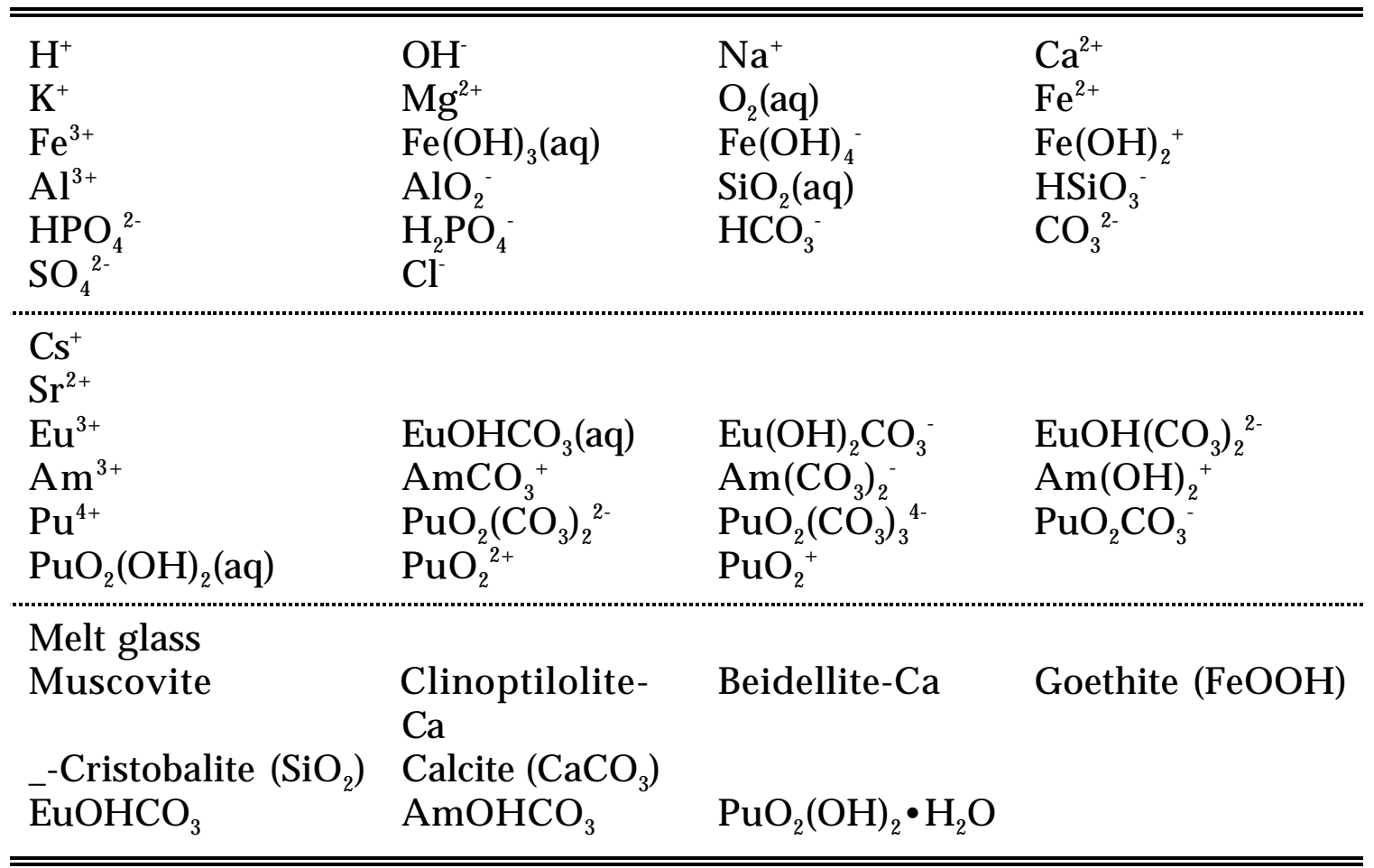

Away from the test, the alluvium was represented by a series of horizontal layers with distinct hydraulic and chemical properties. Within each layer, nonuniform distributions of hydraulic conductivity were specified according to a 
log-normal correlated Gaussian random field model. This served to reflect observed variability in available (yet sparse) conductivity data, although uncertainty in the parametric data required for the model (ln $\mathrm{K}$ variance and spatial correlation scales) and its overall applicability remains and is deserving of additional experimental confirmation [6]. In general, mean conductivity values in the layers (all scalar) ranged from 0.2 to $10 \mathrm{~m} / \mathrm{d}$, with some localized extreme values reaching over 50 $\mathrm{m} / \mathrm{d}$. Correlation scales ranged from $6 \mathrm{~m}$ (vertical) to $24 \mathrm{~m}$ (horizontal in the direction of flow), while $\ln \mathrm{K}$ variances were approximately 2.3. The porosity was assumed to be a uniform value of 0.4 . Hydraulic conductivities in the cavity, chimney, and melt glass zones were assumed to be smaller than those found in the surrounding media. Since the material in the cavity and chimney represents slumped or collapsed alluvium, smaller values seemed appropriate [3,6], even though this would tend to divert flow around radioactive zones abutting the test. The permeability of the glass was assumed to be quite small $(0.04 \mathrm{~m} / \mathrm{d})$, with a porosity of 0.1 . The principal chemical properties of the geologic media were specified in terms of the abundance of reactive minerals in the alluvium and cavity/chimney rubble (Table 5), as well as the specific properties of the melt glass. These will be discussed further in the context of the reactive transport model (below).

Steady flow in the system was induced through specification of a small and fixed hydraulic gradient of 0.001 across the longitudinal axis of the domain, with all lateral boundaries being considered no-flow boundaries. This is consistent with conditions in Frenchman Flat. An earlier calibration of this model incorporated a pumping well to reflect the 16-year migration experiment and the subsequent capture of the tritium inventory shown in Tables 1 and 2 [6]. Remaining simulations incorporated ambient flow conditions only and focused on radionuclides other than tritium. Figure 1 shows a portion of the domain and a series of streamlines that pass through the exchange volume and melt glass zones in the model. These streamlines were integrated from the flow solution and form the basis for the reactive transport simulations discussed below.

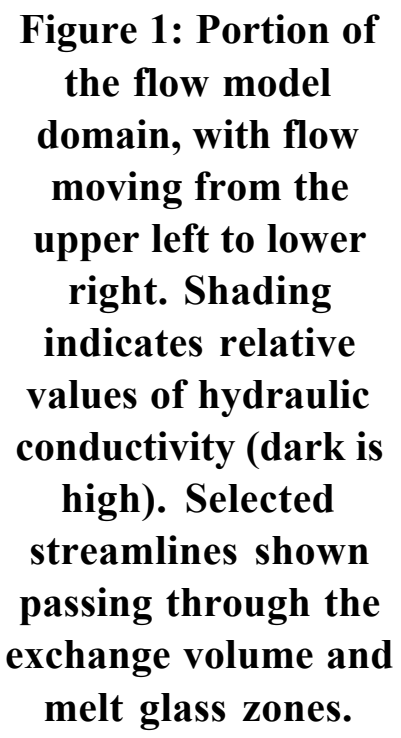




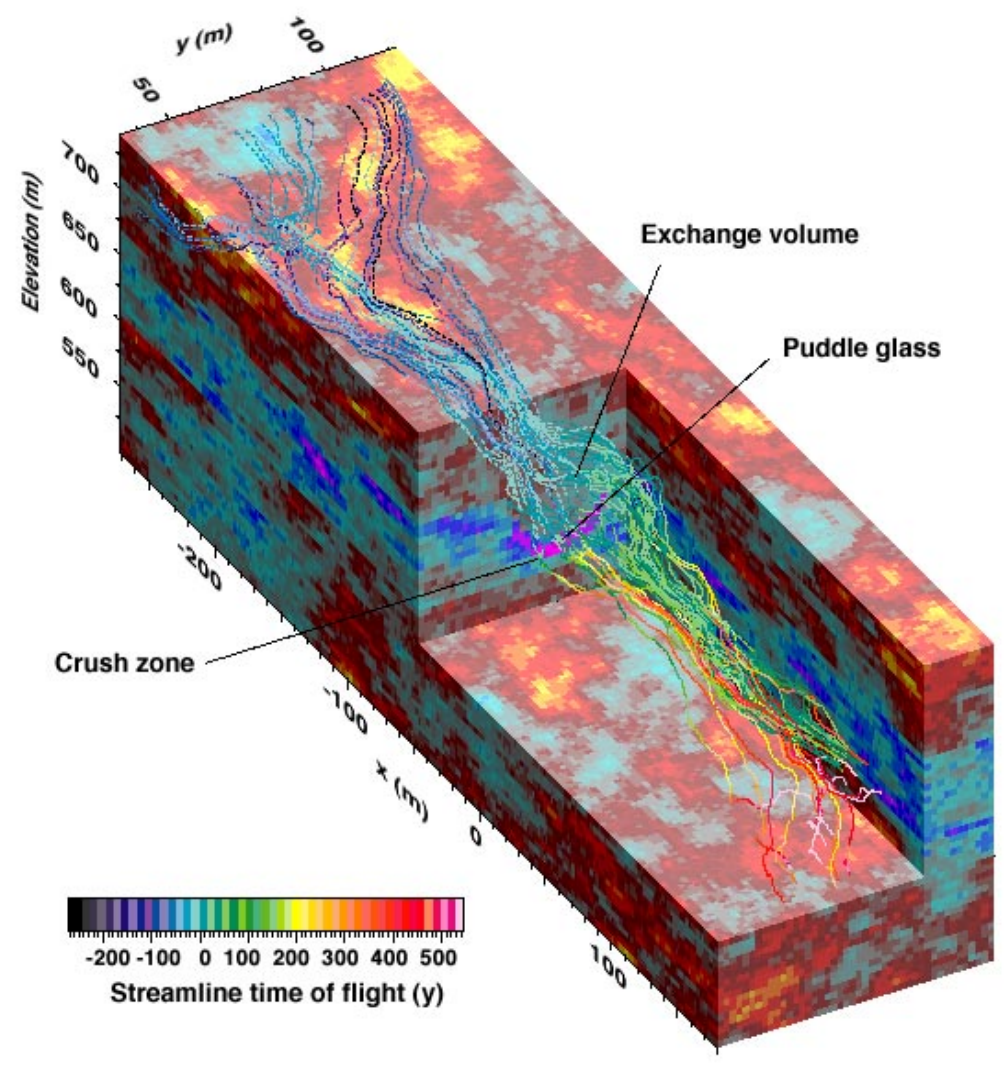

\section{Streamline Transport Model}

Reactive transport simulations were accomplished with a streamline-based transport model. In this approach, a three-dimensional transport problem is recast into a large number of independent one-dimensional reactive transport simulations that correspond in a one-to-one fashion to a large number of streamlines that have been extracted from a simulated three-dimensional flow field $[6,12,13]$ developed on a regular, fixed grid.

The streamline mapping procedure is, in some sense, a regridding process tailored specifically for transport simulations. The procedure used to select the streamlines was constrained by two important issues: (i) a desire to use streamlines passing through the initially-contaminated regions only, as opposed to the entire domain, so as to focus all computational effort on the migrating radionuclides, and (ii) a desire to have at least one streamline passing through each grid block inside of the contaminated zone, so as to provide a numerical basis to "pick up" all of the mass comprising the initial inventory as it is introduced into the aqueous regime. 
Table 5: Distribution of volume percentages used in the simulations for the alluvium/exchange volume and melt glass. Reactive or inert medium configurations are used at different spatial locations in different transport simulations.

\begin{tabular}{cccc}
\hline \hline Phase & Reactive medium & $\begin{array}{c}\text { Inert } \\
\text { medium }\end{array}$ & Melt glass \\
\hline Glass & 0 & 0 & 90 \\
Inert matrix & 47 & 60 & 0 \\
Clinoptilolite-Ca & 5 & 0 & 0 \\
Beidellite-Ca & 5 & 0 & 0 \\
Calcite & 1 & 0 & 0 \\
Muscovite & 1 & 0 & 0 \\
Goethite & 1 & 0 & 10 \\
Pore space & 40 & 40 & 0 \\
\hline \hline
\end{tabular}

This particular approach did not ensure that all grid-blocks downgradient of the initially contaminated region had streamlines passing through them. However, such grid blocks, should they exist, would likely be associated with very low conductivities and a lack of streamline resolution in these regions would be less important from an overall migration perspective. Also, this approach did not inherently allow for mass transfer between streamlines, as would occur from transverse dispersion and diffusion processes. This is recognized as an approximation, although the errors incurred would be smaller in advectively dominated problems such as this, where the resolution of the flow model is relatively large $\left(\mathrm{x}_{\mathrm{i}} \sim 2 \mathrm{~m}\right)$. Altogether, our simulations were based upon 809 streamlines extracted from the flow simulation (Fig. 1).

Along each streamline, the one-dimensional simulations were based upon the GIMRT reactive transport model [14], reconfigured in a "time-of-flight" formulation $[6,12]$ :

$$
\phi \frac{\partial\left(u_{j}+u_{j}^{i m}\right)}{d t}+\phi \frac{\partial u_{j}}{d \tau}-\phi \frac{\partial}{d \tau}\left(\frac{D}{V^{2}} \frac{\partial u_{j}}{d \tau}\right)=-\sum_{m=1}^{N_{m}} v_{j m} r_{m}
$$

In this expression, the curvilinear spatial coordinate along the streamline has been transformed into a time of flight variable (\lrcorner . The concentrations $u_{j}$ and $u_{j}^{i m}$ represent the total mobile and immobile concentrations of radionuclide $j$, each being linear combinations of primary and secondary species that are related through equilibrium mass action relationships [6,12]. Local longitudinal dispersion (D) was not considered in the current work. The rate terms on the right hand side of (2) represent accumulation of radionuclides from dissolution of melt glass or other precipitates, or loss through precipitation of other solids considered in the model (Table 4). Rate laws similar to (1) are used here; surface areas and rates for processes other than melt glass dissolution are discussed in [6]. The effects of radioactive decay are incorporated in an approximate, ex post facto manner by appropriate adjustment 
of concentrations at the end of a simulation. Cumulative impacts of radionuclide decay accrued over the course of a simulation cannot be treated in this manner and must be addressed directly within the model.

Simulations along each line are initiated by assigning the initial aqueous chemistry (Table 3) and appropriate solid phase specification (see below) along the entire line. This may include the melt glass for those portions of the lines passing through the glass volume or the reactive and inert minerals elsewhere. For those lines passing through the exchange volume, the applicable radionuclide inventory is assigned to the appropriate section of the line and distributed among the liquid and solid phases as conditions dictate.

\section{Reactive Mineral Heterogeneity}

The types of reactive minerals (Table 5) are known from mineralogic descriptions of alluvium from two boreholes in the vicinity of Cambric. These descriptions clearly indicate that the mineralogic abundance is spatially variable. Based upon the observation that zeolites are in greatest abundance in a layer with the lowest hydraulic conductivity, we assumed that hydraulic conductivity distribution is inversely correlated with the reactive mineral distribution. This assumption was used in a series of sensitivity simulations to gauge the effects of the mineralogic distribution on the overall elution of radionuclides out of the model system. We also included a simulation with an increased glass dissolution rate, as might be produced by a larger melt glass surface area $\left(\mathrm{A}_{\mathrm{s}}\right)$ or a larger rate coefficient $(\mathrm{k})$ in (1).

Using the terminology of [6], Mineralogic Model 10 assigned the nominal reactive mineral specification (Table 5) uniformly to all points in the model domain. Model 11 assigned an inert mineral specification (Table 5) uniformly to all points in the model domain. Model 12 assigned the reactive specification to the $1 \%$ of the domain with the lowest conductivity values, with an inert specification elsewhere. Model 10a was similar to Model 10, although the nominal goethite surface area was reduced to $50 \mathrm{~m}^{2} / \mathrm{g}$ from $600 \mathrm{~m}^{2} / \mathrm{g}$. Model 13a assigned the reduced goethite specification (as in 10a) to the $80 \%$ of the domain with the lowest conductivity values. Model $10 \mathrm{~d}$ was the same as model 10a, except that the glass dissolution rate was increased by a factor of 100 .

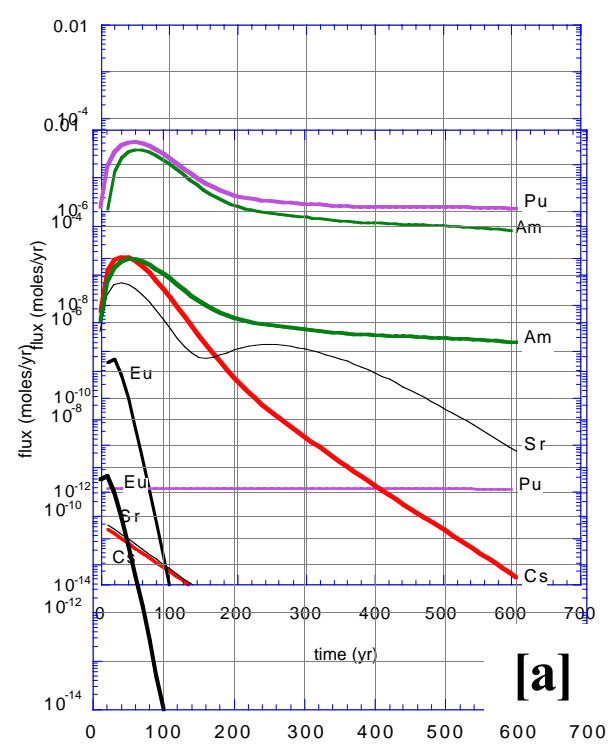

\section{SOME SIMULATION RESULTS}

Figure 2a shows the total flux of the total $\mathrm{Eu}, \mathrm{Am}, \mathrm{Pu}, \mathrm{Sr}$, and $\mathrm{Cs}$ out of the domain over a 600 year period, as integrated over all streamlines, corresponding to Mineralogic Model 10. Because its long half live and lack of retardation, Am shows the most significant breakthrough, with the 5\% exchange volume fraction eluting first and the remaining signal coming from slower dissolution from the melt glass. Although not retarded, the Eu 
breakthrough is much less notable, owing to radioactive decay. The $\mathrm{Pu}, \mathrm{Sr}$, and $\mathrm{Cs}$ fluxes should be considered as " 0 ", since their corresponding concentrations are all below small background levels required in GIMRT. Radionuclide precipitation did not occur in this simulation.

Figure $2 \mathrm{~b}$ shows the total flux of the same radionuclides corresponding to Mineralogic Model 11, in which no reactive minerals were present in the domain. Although the $\mathrm{Am}$ and $\mathrm{Eu}$ results are unchanged, $\mathrm{Pu}, \mathrm{Sr}$, and $\mathrm{Cs}$ now exhibit breakthrough owing to their increased mobility in the system. The only chemical processes affecting elution out of the domain in this simulation are melt glass dissolution and radioactive decay. Most elution curves show the early release of the exchange volume components, followed by a slower release from the glass. $\mathrm{Pu}$ shows the largest release rate because its inventory (Table 1) was the largest of the radionuclides considered.

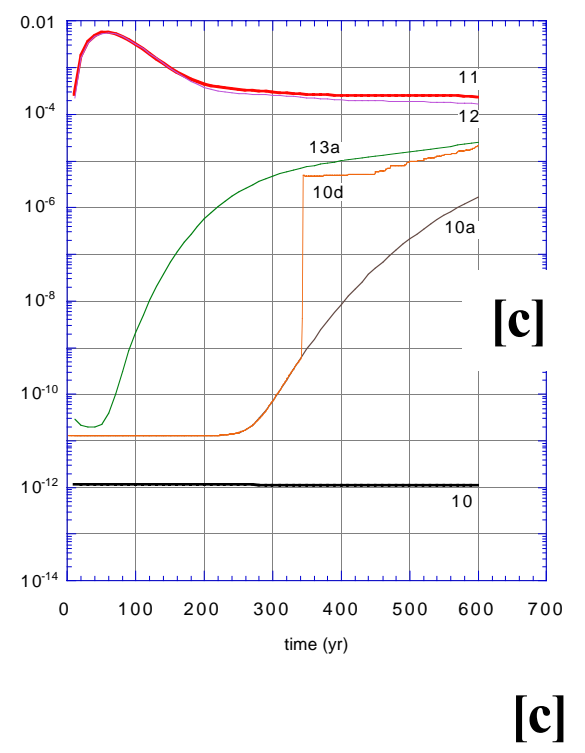

Figure 2c shows the aggregate flux of total $\mathrm{Pu}$ for all mineralogic models considered. The small fraction of reactive minerals in Model 12 slightly affected the

\section{Figure 2: Elution profiles for total $\mathrm{Cs}, \mathrm{Sr}, \mathrm{Eu}, \mathrm{Pu}$, and Am out of the model domain, as based upom Mineralogic Model 10 (a) and Model 11 ( b). Elution profile for $\mathrm{Pu}$ under all Mineralogic Models (10, 11, 12, 101, 13a) shown in (c).}

latter end of the elution curve when compared to Model 11. Comparison of Model 10a to Model 10 shows breakthrough occurs with reduction of the goethite surface area, despite the fact that the reactive minerals are uniformly distributed in both models. The elution profile of Model 10a is enhanced further in Model 13a when the same reactive mineral specification is constrained to be in the $80 \%$ of the materials with the lowest hydraulic conductivity.

Faster flow pathways in higher conductivity regions with no reactive minerals contribute to the increased mobility of Pu. Finally, in comparing Model 10a to 10d, a dramatic increase in the $\mathrm{Pu}$ elution arising from the increased melt glass reaction rate is observed. The elution profile flattens in Model $10 \mathrm{~d}$ when $\mathrm{PuO}_{2}(\mathrm{OH})_{2} \bullet \mathrm{H}_{2} \mathrm{O}$ reaches saturation and precipitates in the melt glass, essentially throttling the aqueous $\mathrm{Pu}$ release.

\section{CONCLUSIONS}

Our simulations indicate that the cavity, chimney, and melt glass environments can act as significant sources of radionuclides for hundreds to thousands of years, or more [6]. Important processes controlling the rates of radionuclide introduction into groundwater include melt glass dissolution and chemical retention effects associated with sorption processes on reactive minerals in the alluvium and cavity/chimney regions. The elution results were particularly 
sensitive to the abundance and distribution of reactive minerals in the system and the dissolution rate of melt glass.

The streamline modeling approach proved to be an exceptionally useful and flexible technique for studying this problem. It allowed a highly resolved 3D reactive transport problem to be decomposed into a large, yet tractable, number of 1D reactive transport problems, whose results could later be recombined into a 3D solution. Solutions were assembled in a piecemeal fashion using less computer time and allowing for problematic aspects of the solution to be solved more quickly. Analysis of preliminary 1D solutions allowed for faster benchmarking of specific sensitivity and design issues, as well as for diagnosis and interpretation of particular transport and reaction behavior before the more time-consuming 3D simulations were performed.

Efforts are underway to measure glass surface areas from retrieved melt glass samples and analog volcanic glasses, as well as to better characterize the mineralogy and heterogeneity of alluvium. Data collection efforts are being planned to better characterize in situ radionuclide concentrations for monitoring and model validation purposes. Field data are critically important for better understanding the relevant physical and chemical processes in the system, as well as for calibrating and validating predictive models.

\section{ACKNOWLEDGEMENTS}

This work was conducted under the auspices of the U. S. Department of Energy by Lawrence Livermore National Laboratory under contract W-7405-Eng-48. This work was funded by the Underground Test Area Project, U. S. Department of Energy, Nevada Operations Office.

\section{REFERENCES}

1. U.S. DOE, Regional groundwater flow and tritium transport modeling and risk assessment of the underground test area, Nevada Test Site, Nevada, U. S. Department of Energy, Nevada Operations Office, Environmental Restoration Division, Las Vegas, NV, DOE/NV--477 (1997).

2. IAEA, The radiological situation at the atolls of Mururoa and Fangataufa. Inventory of radionuclides underground at the atolls. Interim version, Vol. 3, International Atomic Energy Agency, Vienna (1998).

3. I. Borg, R. Stone, H. B. Levy, and L. D. Ramspott, Information pertinent to the migration of radionuclides in ground water at the Nevada Test Site. Part 1: Review and analysis of existing information, Lawrence Livermore National Laboratory, Livermore, CA, UCRL-52078 (1976).

4. L. S. Germain and J. S. Kahn, Phenomenology and containment of underground nuclear explosions, Lawrence Livermore National Laboratory, Livermore, CA, UCRL-50482 (1968).

5. D. K. Smith, Characterization of nuclear explosive melt debris, Radiochimica Acta, 69, 157-167 (1995). 
6. A. F. B. Tompson, C. J. Bruton, and G. A. Pawloski, eds., Evaluation of the hydrologic source term from underground nuclear tests in Frenchman Flat at the Nevada Test Site: The Cambric test, Lawrence Livermore National Laboratory, Livermore, CA, UCRL-ID-132300 (1999), (http:/ / www-ep.es.llnl.gov/wwwep/UGTA, August 2, 1999).

7. D. C. Hoffman, R. Stone, and W. W. Dudley, Jr., Radioactivity in the underground environment of the Cambric nuclear explosion at the Nevada Test Site, Los Alamos National Laboratory, Los Alamos, NM, LA-6877-MS (1977).

8. E. A. Bryant, The Cambric migration experiment: A summary report, Los Alamos National Laboratory, Los Alamos, NM, LA-12335-MS (1992).

9. L. Schwartz, A. Piwinskii, F. Ryerson, H. Tewes, and W. Beiringer, Glass from underground nuclear explosions. Journal of Noncrystalline Solids, 67, 559-591 (1984).

10. J. J. Mazer, Kinetics of glass dissolution as a function of temperature, glass composition, and solution pH, Ph.D. thesis, Northwestern University (1987).

11. R. G. Baxter, Description of defense waste processing facility reference waste form and container, Savannah River, Aiken, SC, DP-1606, rev. 1 (1983).

12. M. R. Thiele, R. P. Batycky, M. J. Blunt, and F. M. Orr, Simulating flow in heterogeneous systems using streamtubes and streamlines, SPE Reservoir Engineering, 10, 5-12 (1996).

13. S. B. Yabusaki, C. I. Steefel, and B. D. Wood, Multidimensional, multicomponent, subsurface reactive transport in nonuniform velocity fields: code verification using an advective reactive streamtube technique, Journal of Contaminant Hydrology, 30, 299-331 (1998).

14. C. I. Steefel and S. B. Yabusaki, OS3D/GIMRT, Software for modeling multicomponent and multidimensional reactive transport, User manual and programmer's guide, Version 1.0, Pacific Northwest National Laboratory, Richland, WA, PNL-11166 (1996). 